\title{
THE KARAKURI CARD DECK: CO-DESIGNING INDUSTRIAL IOT CONCEPTUAL SOLUTIONS
}

\author{
Á. Aranda Muñoz ${ }^{1,2, \bigotimes}$, U. Florin ${ }^{1}$, Y. Eriksson ${ }^{1}$, Y. Yamamoto ${ }^{1}$ and K. Sandström ${ }^{2}$ \\ ${ }^{1}$ Mälardalen University, Sweden, ${ }^{2}$ RISE, Sweden \\ $\triangle$ alvaro.aranda.munoz@mdh.se
}

\section{Abstract}

Novel IoT market solutions and research promise IoT modules that do not require programming or electrical setup, yet shop floor personnel need to face problem solving activities to create technical solutions. This paper introduces the Karakuri card deck and presents a case study composed of four workshop sessions in four manufacturing settings, where shop floor personnel tested the cards as a means of ideating and presenting conceptual IoT solutions in the form of diagrams. The results indicate the validity of the proposed conceptual solutions and suggest prototyping as a next step.

Keywords: case study, participatory design, internet of things (IOT), early design phase, idea generation

\section{Introduction}

In industrial settings, shop floor personnel often face simple problems such as the supervision of inventory, moving work orders around the factory or checking the status of machines which may be located at a distance from each other and which often lead to long walks in industrial environments. These problems could be addressed with Internet of Things (IoT) technology, which can be defined as a set of identifiable physical sensing and actuating devices communicating across a network (Miorandi et al., 2012). However, shop floor personnel seeking solutions for these problems lack the necessary computational and making literacy.

The decreasing price of sensor hardware and the market availability of new IoT products that require less computational knowledge brings new opportunities to these industrial settings. However, "developing IoT solutions is still a complex, time-consuming and challenging activity" due to the combination of software, hardware and communication modules (Udoh and Kotonya, 2018). Hardware such as the Arduino has empowered makers and "people who may not have previously worked with hardware" to create their own prototypes (Rowland et al., 2015); the maker community, however, is knowledgeable in electronics and programming. To address this complexity, companies have created a new wave of products such as Sony MESH, SAM Labs and littleBits that mask some of the complexity, leading to modular hardware components that simplify the creation of circuits and programming. These modular components enable non-experts to create simple prototype solutions with sensors and actuators.

The commercial availability of such products is only a first step for non-experts, as there is still the need to develop a "computational-thinking" perspective that allows users to break down problems, and formulate them in a way that allows computers to solve the problem (Tissenbaum et al., 2017). 
Computational thinking has been widely explored by educators and researchers specialising in child learning (Tedre and Denning, 2016; Farris and Sengupta, 2016), as it addresses the need to extend computational thinking to computational making due to ubiquitous technologies (IoT) and the maker culture (Rode et al., 2015). From a design perspective, the ideation and creation of conceptual solutions can be supported with design techniques such as the use of design cards, which "can support different phases of a design process, from initial ideation through ongoing concept development towards evaluation of design concepts" (Lucero et al., 2016).

Empirically, the presented study employs a design perspective in considering how, through a bottomup approach, shop floor personnel can be supported in the conceiving of IoT conceptual solutions which address daily routine problems and allow them to capitalize on opportunities. To explore this perspective, we created the Karakuri card deck and have carried out a case study composed of four workshops in a variety of large manufacturing companies in Sweden. The goal was to observe whether shop floor personnel are able to ideate valid IoT conceptual solutions with the help of the Karakuri cards. The intention is that at a later stage, shop floor personnel can prototype their proposed conceptual solutions by themselves.

\section{Background}

This study is part of a three-year research project that started in 2018 named "Karakuri IoT". The goal of the project is to create a hardware and software modular kit of sensors tailored for industrial purposes that is simple for shop floor personnel to use (Yamamoto et al., 2018a; Yamamoto et al., 2018b). The research project involves a university department specialized in design and improvement of production systems and a research department of Information Design, two research institutes and six manufacturing companies (four large and two small companies) all located in Sweden. The team involved in the main activities of the project is multidisciplinary and is composed of a senior researcher specialising in industrial IoT, a researcher on Kaizen and lean production, and an interaction designer.

The Karakuri IoT project is inspired by the Karakuri Kaizen movement. Kaizen refers to "work improvements" and is considered "an activity that, with just a little effort, makes work easier, improves efficiency or increases safety" (Kumashiro, 2011). The term Karakuri can be translated from the Japanese as "mechanism" or "trick", and in manufacturing settings is defined as "sophisticated mechanical contrivances utilising natural energy" (Katayama, 2017). Combining both words (Karakuri and Kaizen) the movement is based on creating improvements in manufacturing settings by using mechanical devices that facilitate automation. These improvement devices are normally created by shop floor personnel and do not need an external source of power. Devices rely on mechanical design which takes advantage of natural forces such as gravitation in combination with pulley systems to automate or semi-automate different activities in the manufacturing processes.

The goal of Karakuri IoT is to incorporate the advantages produced by IoT into the Karakuri Kaizen movement by including low-cost sensor solutions designed and prototyped by shop floor personnel. However, shop floor personnel lack the computational and electronic skills to create IoT solutions. Therefore, the approach of Karakuri IoT is to design and create the necessary resources for shop floor personnel so that despite a deficiency of computational literacy, they are able to ideate and prototype IoT solutions. To this purpose, the team is currently developing a modular hardware and software system that is simple to use (knowledge of electronics or programming skills is not required), and the Karakuri card deck, specifically designed to support the ideation of IoT solutions in industrial settings. The ideation and prototyping of IoT solutions are divided into four stages, in which the team proposed a workshop-based methodology for shop floor personnel empowerment (Yamamoto et al., 2018b):

- Stage 1 Workshops. Participants brainstorm problems and opportunities for improvement, drawing examples from their daily work.

- Stage 2 Workshops. Participants ideate conceptual solutions to address the improvement opportunities identified in Stage 1.

- Stage 3 Workshops. Participants prototype the conceptual solution of Stage 2 in a laboratory environment using the software and hardware IoT modules.

- Stage 4 Workshops. Participants test a refined prototype in the manufacturing environment. 
In this paper, the focus is on Stage 2 (see Figure 1), in which the team identified an opportunity to support shop floor personnel in the ideation and conceptualisation of IoT solutions using the Karakuri deck. The case study presents two studies where the deck was used: the first study included a pilot workshop, where the Karakuri cards were used for the first time; the second study consists of three workshop sessions (A, B, C) with redesigned cards based on the findings of the first study.

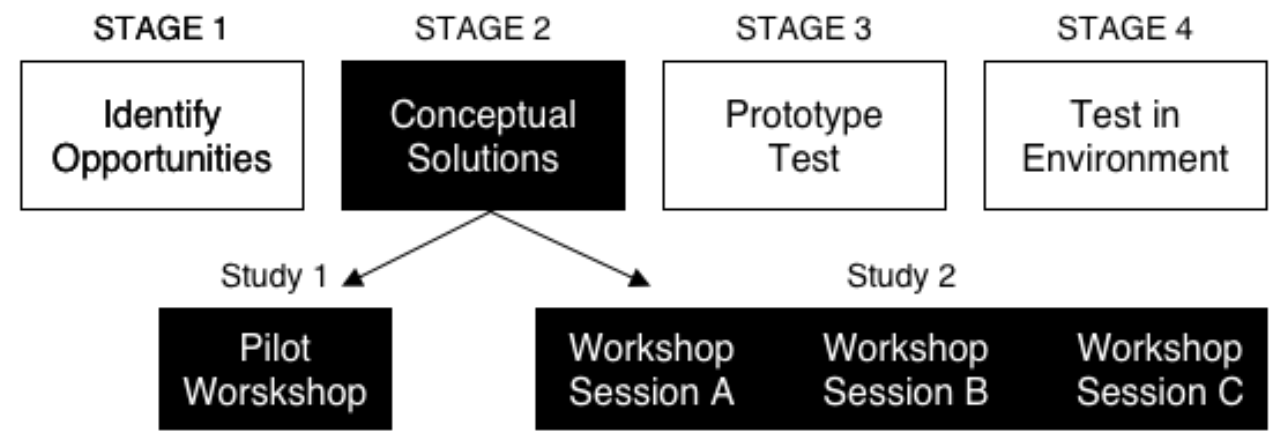

Figure 1. Organisation of the Karakuri loT Stage 2 Case-study

\section{Theory}

Design cards are common tools in design that, among other things, can support the use of design methods to emphasise human values in the design process (Friedman and Hendry, 2012), can inspire sustainable awareness (Ræbild and Hasling, 2018), and can support discussion and collaboration in a variety of professions, as for example with the 42 commercially available Methodkit Cards (2012). In the domain of IoT, there are card decks that support the designing of IoT products for designers (Chen, 2011), the invention of smart objects or connected products by non-experts (Mora et al., 2017) and the co-designing of IoT solutions (Brito and Houghton, n.d.) and connected products from a User Experience perspective (Dibitonto et al., 2018); however, to our knowledge, IoT design cards tailored to meet the demands in industrial manufacturing settings do not yet exist.

Wölfel and Merritt (2013), in their survey of 18 card-based design tools, identified five design dimensions: intended purpose and scope, the duration of the process in which the cards are used, the methodology employed, the level of customisation that the cards permit and the formal qualities of the cards. From a cognitive perspective, the formal quality of physical paper cards presents visual communications that are "permanent" and can therefore "be mentally assessed and rearranged in multiple ways that contribute to understanding, inference, and insight" (Tversky, 2011). The cards, physical artefacts, are handled by participants in a social context, and in the physical space in which there are interactions between participants and the cards. These cards are arranged in a space (A3 paper, whiteboard), in which participants draw lines, arrows, and other glyphs with the aim of making associations and forming diagrams, which "convey certain information clearly in ways that are easily apprehended" (Tversky, 2011). Hornecker and Buur (2006) propose a framework for design analysis and guidance on tangible interaction that distinguishes four different themes: tangible manipulation, spatial interaction, embodied facilitation and expressive representation.

\section{Method}

Design workshops (Martin et al., 2012) were selected as the primary method of carrying out these studies. The team held the role of facilitators in the planning and execution of the activities in order to observe participants, following a co-design approach (Sanders and Stappers, 2008). As part of this method, the workshops included participant's presentations of the problem to be solved and ideation techniques needed to create and diagram solutions with the support of the Karakuri cards. These solutions were then described by participants through storyboards (Martin et al., 2012) that reflected the use in context of the IoT solution and the actors involved. As a final step for each workshop, a spontaneous open discussion was held in which the participants shared their reflections on the workshop and the cards. 
The research project design workshops are described in regard to the preparation, the execution, and the gathering of material, in the following subsections.

\subsection{Preparation}

The preparation for the workshops included a presentation with a simple description of the Karakuri Methodology (Yamamoto et al., 2018b) in which the Karakuri cards were showcased. The material consisted of a deck of cards for each group of participants, an overview summarizing all of the Karakuri Cards needed to facilitate navigation, storyboard templates and common material (A3 paper, sticky notes, tape, and glue).

The workshop participants depended on the shop floor personnel available at the different companies, with diversified roles in production, namely: technicians, operators of machinery, logistic personnel, maintenance, and IT personnel. With the inclusion of a diverse group of participants, the team sought to represent the shop floor personnel in a broad sense.

\subsection{Execution of the workshops}

The duration of the workshops varied from two to two and a half hours, depending on the number of participants involved. All workshops started with a 15-minute introduction to the workshop and the Karakuri deck of cards, using the same presentation slides for all groups. In this introduction, a general idea of the Karakuri Kaizen movement and the research project was presented in combination with a brief agenda and the participants' goal for the workshop: to find conceptual solutions for a selected problem.

Next, the shop floor personnel had 15 minutes to introduce the problem to be solved and 60 minutes to work on conceptual solutions with the Karakuri card deck. As a way to document the results, shop floor personnel filled the Karakuri storyboard template (15 minutes) and presented the result to the rest of the participants (15 minutes). As a final step, the team held a reflective discussion with all participants that lasted approximately 30 minutes.

\subsection{Gathering of workshop material}

The research carried out in this study is based on a qualitative method. The data collected during the workshops can be summarised as: annotations and observations by the team during the workshops, twenty-one conceptual solutions created by shop floor personnel, storyboards demonstrating how potential solutions would work in the factory, the designed decks of cards tested with participants, pictures at different stages of the workshop, and the annotations from the spontaneous open discussions held after each workshop in which shop floor personnel presented their final solutions.

During the workshops, there were always at least three members of the team following the flow of action, observing, and taking notes. After each workshop, the resulting conceptual solutions and storyboards were gathered by the team and digitalised. Hand-written notes were transcribed with the date and place of each workshop. All materials from each workshop were archived both physically and digitally by the team and categorised according to the company and the workshop number. It is possible to track the date and the member of the team who took the notes.

\section{The case study}

The design journey to create a deck of cards for shop floor personnel started with the recollection of problems and opportunities in Stage 1, in which shop floor personnel engaged in brainstorming activities in order to list and document more than 80 problems and opportunities (Yamamoto et al., 2018b). The resulting material from these stage 1 workshops was helpful for analysis in the industrial context and for determining what types of sensors and technologies would help to create conceptual solutions. This was the origin of a list of components that formed the basis of the first deck of 42 cards. These cards (see Figure 2) included multi-coloured icons selected from an online library (Flaticon, 2019), represented the technology and a title with the technological term, and were to be glued to the A3 paper of the final conceptual solution, but at this stage were referred to as "stickers". 

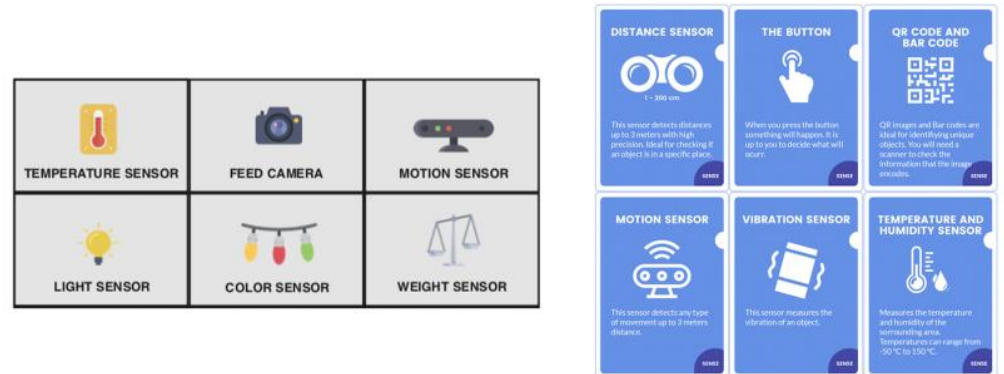

Figure 2. Evolution of the card deck, from stickers that represent hardware modular components (left) to cards that include a brief description of each component (right)

The case study is composed of two studies: the first includes the initial pilot workshop (Yamamoto et al., 2018a) in which the first set of cards (stickers) was tested and later redesigned to better fit participant needs. The second study includes the following three workshop sessions, where the redesigned cards were tested.

Table 1. Case study workshop sessions

\begin{tabular}{|c|c|c|c|c|}
\hline & Pilot Session & Session A & Session B & Session C \\
\hline Type of deck & Stickers & Cards & Cards & Magnetic Cards \\
\hline Context & A3 paper on table & $\begin{array}{l}\text { A3 paper on } \\
\text { table }\end{array}$ & $\begin{array}{l}\text { A3 paper on } \\
\text { Table }\end{array}$ & $\begin{array}{l}\text { Magnetic } \\
\text { Whiteboard }\end{array}$ \\
\hline Size of cards & $6 \mathrm{~cm} \times 4 \mathrm{~cm}$ & $6,5 \mathrm{~cm} \times 8,6 \mathrm{~cm}$ & $6,5 \mathrm{~cm} \times 8,6 \mathrm{~cm}$ & $6,5 \mathrm{~cm} \times 8,6 \mathrm{~cm}$ \\
\hline Problem solved & $\begin{array}{l}\text { "Washing basket } \\
\text { availability and } \\
\text { status" }\end{array}$ & $\begin{array}{l}\text { "Find work } \\
\text { order", } \\
\text { "machine stop" }\end{array}$ & $\begin{array}{l}\text { "Lack of carton", } \\
\text { "Modify machine } \\
\text { alarms that are } \\
\text { stressful" }\end{array}$ & $\begin{array}{l}\text { "When to fetch } \\
\text { cabin with forklift", } \\
\text { "Identify chassis" }\end{array}$ \\
\hline Colour-coded & No & Yes & Yes & Yes \\
\hline No. cards & 42 & $\begin{array}{l}27+5 \text { joker } \\
\text { cards }\end{array}$ & $27+5$ joker cards & $27+5$ joker cards \\
\hline No. Participants & 7 & 7 & 7 & 7 \\
\hline No. Groups & 2 & 3 & 3 & 2 \\
\hline No. Problems & 1 & 2 & 2 & 2 \\
\hline No. Solutions & 6 & 5 & 5 & 5 \\
\hline
\end{tabular}

\subsection{Findings from the observations of the pilot study}

The cards provided a common language among participants (Yamamoto et al., 2018b), who refer to the terminology employed in the title of the cards when discussing concepts. These discussions took place at a conceptual level, as participants didn't discuss the specifics of how the technology would be integrated into the current systems at the manufacturing site. Instead, the focus of the discussions was on exploring the context of the problem and how certain Karakuri Cards could help in finding a solution.

One obstacle observed during the workshop was that participants had problems finding specific cards. They relied on the summary of cards to know which card they needed, but it took them a few seconds to locate the card among those on the table. Furthermore, the deck only included one card from each module, so if, for example, a card depicts an LED, participants will need four or five LED cards to find a solution. In some situations, they relied on the extra Karakuri Decks available to use an extra copy of a specific card. Otherwise they would note and/or sketch-out the extra cards needed with a pen.

Another obstacle observed was that a few participants questioned "what does this sensor do". The accelerometer is an example of a sensor whose function might not be evident from its name. In this case, other participants were able to help explain the sensor and the discussion continued without the intervention of facilitators. As part of a following discussion, one of the participants showed his interest in following the conversation on the whiteboard. This interest in the conversation on the whiteboard triggered a redesign of the deck before Session C. 


\subsection{Redesigning the pilot study Karakuri deck for sessions $A, B$, and $C$}

From the pilot-study findings of section 5.1, the team identified several redesign opportunities, such as the inclusion of a brief description of each technology on each card, so that shop floor personnel could read and refer to it in case of doubt. This was especially useful in addressing sensor functions which were not always evident. This implied a redesign of the size of the cards, from $6 \mathrm{~cm} \mathrm{x} 4 \mathrm{~cm}$ to $6.5 \mathrm{~cm} \mathrm{x}$ $8.6 \mathrm{~cm}$.

In some situations, during the pilot-study, shop floor personnel needed extra copies of each card. The team considered the inclusion of three copies of each card. However, the inclusion of copies would affect the ease with which participants could retrieve cards, which was an identified obstacle during the pilot-study. Including even three copies did not preclude participants from using 4 or even 5 copies for a single solution. The team decided to include additional "joker" cards to represent technologies or ideas that were not included in the deck of cards, and to address the issue of needing multiple copies of one card. Furthermore, to facilitate the identification and retrieval of cards, cards were sorted into four different colour-coded categories: "sense", "notify", "analyse" and "joker". The colour-coded cards employed homogenous iconographical manner, with the icon in white and the colour-coded category in the background.
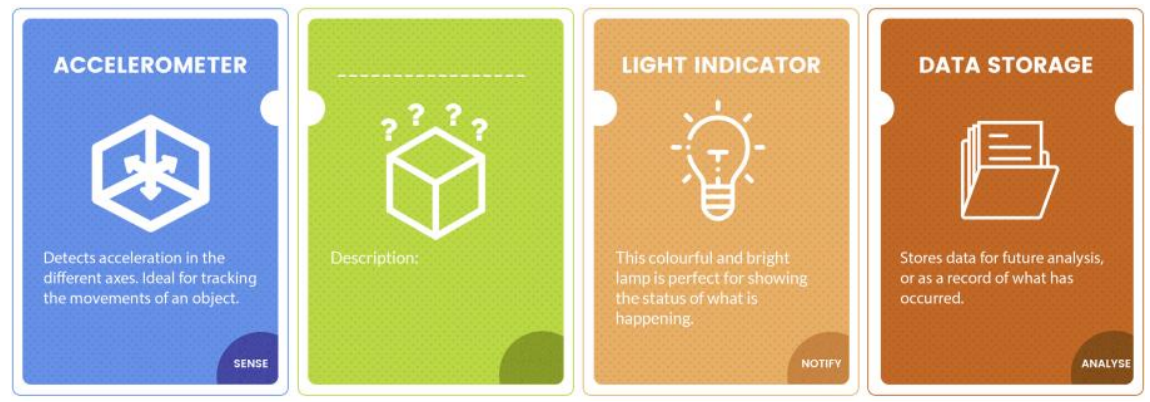

Figure 3. The new iteration of Karakuri cards included a brief description and four different colour-coded categories: "sense", "notify", "analyse", and "joker"

Considering the conceptual discussions held during the pilot, the team decided upon a framing of discussions around the conceptual solution without getting into the technological details underlying the new IoT products. Therefore, more technical cards were removed from the deck, namely: "artificial intelligence", "cloud computing", "security", "Wi-Fi network", "wireless", "trend analytics", "compare chart", and "cloud". Similarly, terms that could be used in almost any situation were removed, (e.g. the "maintenance" and "safety" cards). Two sensor cards based on technology scouting were removed ("air quality" and "flow").

The observation about the participant who wanted to use the whiteboard to discuss the problem initiated a new design concept: magnetizing cards for use on a magnetic whiteboard, which was implemented for session C. It was not implemented earlier because the first analysis of the pilot observations did not trigger this response. It was in a later revision before Session $\mathrm{C}$ that the observation was questioned as a design alternative to be considered.

\section{Findings from the observations of workshop sessions A, B, and C}

The resulting 27 re-designed cards (plus the additional 5 "empty" jokers), with all the changes mentioned in section 5.2 constituted the second iteration of the Karakuri Deck. This deck was tested in the second study, composed of workshop sessions A, B, C.

During this study, it was observed that participants used the Karakuri cards in combination with drawing boxes, lines, and arrows to discuss and present their final solutions (Figure 4). Lines and arrows, in the final solutions, depict relationships and actions between the IoT technologies, as well as users of those technologies and the manufacturing equipment involved. Participants also added notes next to cards, giving more details about how the cards would work in the solution. For example, next to the "light indicator" card they include the word "green" in combination with the word "finish" to indicate that when the process is finished, the light would illuminate green. 
In most of the solutions, participants draw parts of the physical layout of the factory schematically (Figure 4) with the Karakuri cards as placeholders for the IoT technologies. For the remaining solutions, rather than locations, participants drew factory machinery to indicate where the sensors would be placed in order to retrieve specific information for solving the problem. In both situations, cards acted as a physical representation of the technology.
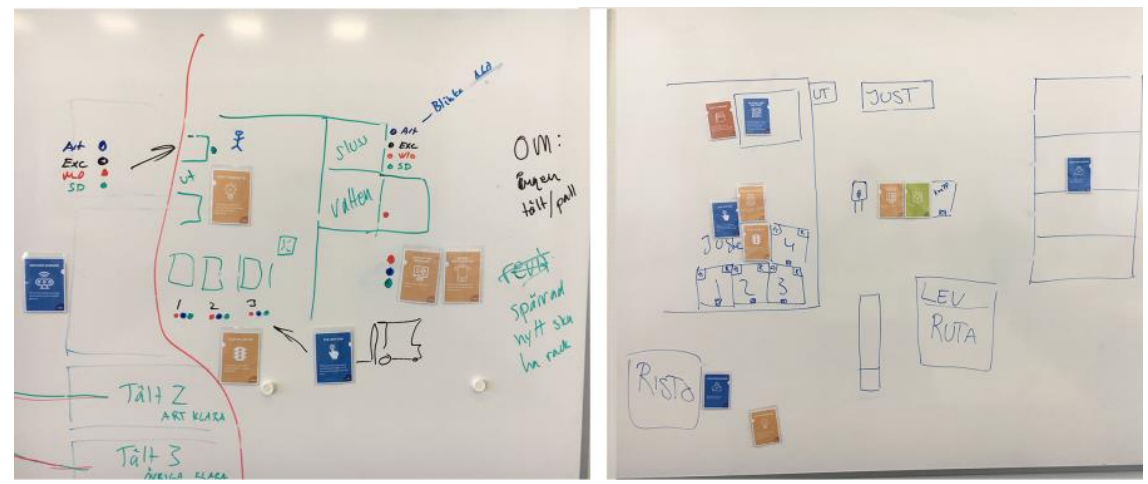

Figure 4. Two of the final solutions; Participants sketch the factory layout in order to communicate where each loT component would be placed and how the solution would work

Participants chose cards, pointed to them, and used them in role-playing explanations of how a technology would be used. For example, one participant proposed using "distance sensors" to detect the arrival of new objects at his workstation. The participant shook the "distance sensor" card to indicate the distance sensor detecting a new incoming object. The incoming object was depicted by the participant with a hand gesture, with one finger pointing downwards.

In one Session B group, a production engineer assumed a more leading role than the other two participants in the same group, especially when discussing the technicalities of the problem. This started a reflection about how to level the knowledge gap among different shop floor personnel. As a potential solution, Mora et al. (2017) discuss the inclusion of turns or game-rules to facilitate more balanced participation.

In session $\mathrm{C}$, the cards included magnets to enable the use of the cards on a magnetic whiteboard, as can be seen in Figure 4. This new use context triggered new observations. One example is that participants moved within the space to demonstrate intention to participate, moved to the side to retrieve new cards and moved to the centre of the action to affix and discuss the cards. Furthermore, the whiteboard served as a more collaborative environment than A3 paper when presenting the final solution, as all participants would gather at a distance and could follow the discussion. When the solutions were presented on A3 paper (in the pilot and in sessions A and B), it was more difficult to gather around the A3 paper and follow the discussion, as the rendering of the solutions was smaller than on the whiteboard.

\section{The Karakuri cards}

The resulting Karakuri deck represents a combination of modular IoT technology that can be used by shop floor personnel to conceptually solve common problems presented in industrial settings by shop floor personnel.

Attending to the five dimensions identified by Wölfel and Merrit (2013) Karakuri IoT cards act as a "repository card system" of IoT technologies to inspire participants and "stimulate design problem solving in general". Karakuri Cards are made from paper $(6,5 \times 8,6 \mathrm{~cm})$. Each card is one-sided, with a title and an icon selected from an online library (Flaticon, 2019) that depicts a technology, a text description of the technology, and a colour-coded background categorising the technology attending to sense (blue), notify (orange), analyse (maroon) and jokers (green). The backside of the cards is magnetized, so cards can be used on both a table and on magnetic whiteboards. The card system includes one copy of each card. The intended use of the cards is for workshops during stage 2 of Karakuri IoT (see Figure 1), the phase of ideating conceptual IoT solutions, which lasts approximately 1 hour. Attending to the methodology of use, Karakuri cards don't present strict rules to follow. The cards are 
always used in the context of a design workshop, in which a problem previously identified by shop floor personnel is presented by shop floor personnel, and the activity duration of the workshop varies from 2 hours to 2 hours and a half as is discussed in the method section. The Karakuri Deck offers "optional customization", as it allows for the deck to be customized and updated by including joker cards.

The Karakuri Cards consider tangible interaction and social interaction following the four dimensions proposed in Hornecker and Buur's (2006) framework. Participants directly handle the cards and affix them to magnetic whiteboards, engage in spatial interaction as they spread out the Karakuri cards in a space, arrange them to suggest potential solutions in the form of diagrams, point at them to suggest ideas and hold them to show intent of use and negotiation to other participants. Participants select cards to use, and discard, at a distance from the working area, the cards that most likely will not be used in the solution. This division of groups of cards organised attending to proximity relates to the organization of metaphoric spaces presented by Tversky (2011).

Regarding embodied facilitation, the initial setup of the pilot and sessions A and B invited participants to use the table as the workspace, where participants were situated around the table at fixed positions that constrained body movement yet enabled a democratised space in which each participant could be close to the action. In session $\mathrm{C}$, participant interactions occurred close to the magnetic whiteboard, where participants used their bodies in space to show intent, to collaborate, and to help. Participants could be far from the ongoing discussion, to reflect and think of the overview and come back with new ideas, and could be at the side to choose new cards, and could navigate through other participants to be at the centre of the action where they could propose a new solution. The different setups can be seen in Figure 5.
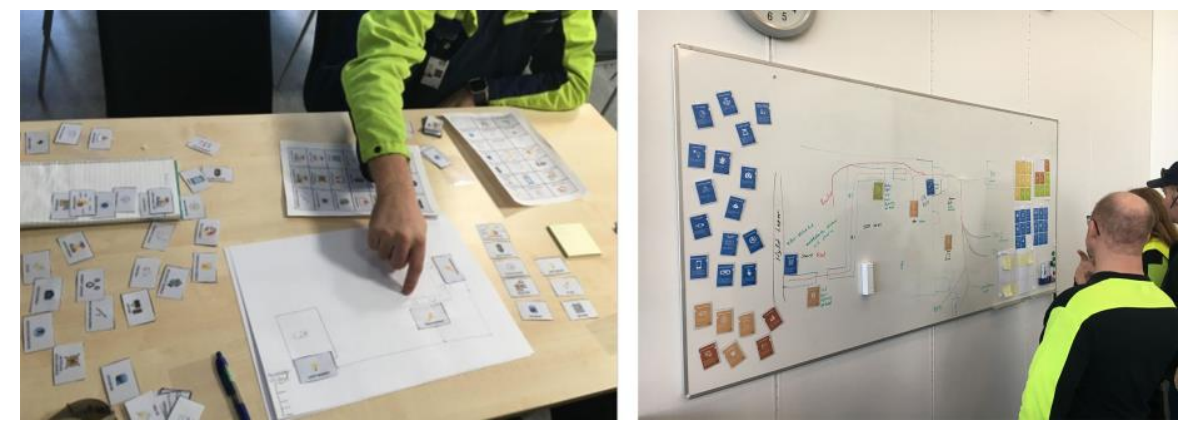

Figure 5. Pilot session (left) and Session C (right)

As expressive representation, the physical cards embody common IoT technologies, providing a common IoT language that enables communication among participants from a diverse range of industrial backgrounds. This content frames the discussion at a conceptual level, abstracting the difficulties hidden in IoT solutions, such as how to connect to a database, network issues, and logical programming. The aim is to facilitate this process in a later phase (Karakuri IoT Stage 3) that will be focused on computational thinking and prototyping and will consider incorporating digital augmentation in the cards (Zhao et al. 2009; Wölfel and Merritt, 2013).

\section{Discussion}

The ten groups of participants that took part in the four workshop sessions were all capable of understanding the problem they were faced with, were able to engage in discussions using the technological terminology of the different Karakuri cards, and could present conceptual solutions that (according to the IoT expert involved in the project) are considered valid for implementation with the modular hardware kit at a later stage. The validity of the conceptual solutions is limited in the sense that diagrams "are incomplete and can be abstract, requiring filling in, bridging inferences" (Tversky, 2011); however, in addition to the diagrams, the IoT expert attended all the conceptual solution presentations in which the conceptual solutions were presented with storyboards. We see the combination of diagrams with storyboard presentations as powerful enough to assess the validity of a concept as a first step, keeping in mind that the team intends to continue the research to assess whether or not the same floor-shop personnel can take a step forward and prototype valid solutions based on the concepts presented. 
As a reflection from the study, we observed an unexpected feature that emerged with the use of the cards: participants, when discussing potential solutions used the cards to role-play (e.g., showcasing when a specific sensor had detected movement). The authors wonder how to design for this emerged property and how this role-play opportunity could improve the presented method. One solution could be to design the Karakuri deck as a business origami kit to create a "theatre-scene" where participants not only discuss the cards, but also move pieces and role-play whole scenarios in order to uncover unexpected unknowns. This role-playing activity could be recorded as a way of documentation, instead of asking participants to draw storyboards. Furthermore, following this new feature of roleplaying, we see that the deck lacks a representation of the users, which can be addressed in a future iteration of the Karakuri deck.

\section{Conclusion}

This paper presented a card-based workshop experience tested in four manufacturing settings in which the team explored how industrial personnel engage and interact in problem solving activities to originate their own IoT conceptual solutions using the Karakuri card deck, which has been presented and discussed in relation to the five dimensions identified by Wölfel and Merrit (2013), and Hornecker and Buur's (2006) framework.

Our findings indicate that shop floor personnel, when provided with the Karakuri cards, can ideate IoT solutions at a conceptual level in order to solve real problems and take advantage of opportunities within industrial settings. To reach the final conceptual solution, in the form of a diagram, participants drew factory locations and machinery schematically, arranging the cards, and indicating the relationships among technologies, places, and people with lines and arrows. The cards help to frame the discussion at a high-level, to share a common language in industrial interdisciplinary teams, and to explore and draw diagrams that represent the final conceptual solution. We see these conceptual solutions as a necessary step before shop floor personnel engage in computational thinking and prototyping, which is considered the next stage.

As a follow-up to this project, the team sees the need to expand this deck and create other artefacts that support - as this deck of cards aids problem solving - other activities such as exploring scenarios through role-playing and presenting a solution in terms of computational thinking. This computational thinking solution would be a first step towards using software that could allow for the behaviour of sensors to be set for a high-fidelity functioning prototype.

\section{References}

Brito, R. and Houghton, P. (n.d.), "IoT Service Kit", available at: http://iotservicekit.com/ (accessed 14 November 2019).

Chen, Y.H. (2011), "IoT deck: a digital card-based ideation game to inspire internet of things design", in 4th World Conference on Design Research, Proceedings of IASDR2011, Netherlands.

Dibitonto, M. et al. (2018), "The IoT Design Deck: A Tool for the Co-design of Connected Products", in Ahram, T. and Falcão, C. (Eds.), Advances in Usability and User Experience, Vol. 607, Springer International Publishing, Cham, pp. 217-227. https://doi.org/10.1007/978-3-319-60492-3_21

Farris, A.V. and Sengupta, P. (2016), “Democratizing Children's Computation: Learning Computational Science as Aesthetic Experience: Democratizing Children's Computation”, Educational Theory, Vol. 66 No. 1-2, pp. 279-296. https://doi.org/10.1111/edth.12168

Flaticon (2019), Flaticon, available at: https://www.flaticon.com/ (accessed 14 November 2019).

Friedman, B. and Hendry, D. (2012), "The envisioning cards: a toolkit for catalyzing humanistic and technical imaginations", Proceedings of the 2012 ACM Annual Conference on Human Factors in Computing Systems - CHI '12, presented at the 2012 ACM annual conference, ACM Press, Austin, Texas, USA, p. 1145. https://doi.org/10.1145/2207676.2208562

Hornecker, E. and Buur, J. (2006), "Getting a Grip on Tangible Interaction: A Framework on Physical Space and Social Interaction", Proceedings of the SIGCHI Conference on Human Factors in Computing Systems, ACM, New York, NY, USA, pp. 437-446. https://doi.org/10.1145/1124772.1124838

Katayama, H. (2017), "Legend and Future Horizon of Lean Concept and Technology", Procedia Manufacturing, Vol. 11, pp. 1093-1101. https://doi.org/10.1016/j.promfg.2017.07.227

Kumashiro, M. (2011). "Kaizen: Ergonomics Approach to Occupational Health and Safety", Journal of Human Ergology, 2011, 40 巻, 1_2 号,p. 163-167, 公開日 2014/11/13, https://doi.org/10.11183/jhe.40.163 
Lucero, A. et al. (2016), "Designing with Cards", in Markopoulos, P., Martens, J.-B., Malins, J., Coninx, K. and Liapis, A. (Eds.), Collaboration in Creative Design, Springer International Publishing, Cham, pp. 75-95. https://doi.org/10.1007/978-3-319-29155-0_5

Martin, B., Hanington, B. and Hanington, B.M. (2012), Universal Methods of Design: 100 Ways to Research Complex Problems, Develop Innovative Ideas, and Design Effective Solutions, Rockport Publishers.

MethodKit Cards (2012), MethodKit, available at: https://methodkit.com/ (accessed 14 November 2019).

Miorandi, D. et al. (2012), "Internet of things: Vision, applications and research challenges", Ad Hoc Networks, Vol. 10 No. 7, pp. 1497-1516. https://doi.org/10.1016/j.adhoc.2012.02.016

Mora, S., Gianni, F. and Divitini, M. (2017), “Tiles: A Card-based Ideation Toolkit for the Internet of Things", Proceedings of the 2017 Conference on Designing Interactive Systems - DIS '17, presented at the the 2017 Conference, ACM Press, Edinburgh, United Kingdom, pp. 587-598. https://doi.org/10.1145/3064663. 3064699

Ræbild, U. and Hasling, KM. (2018), "Sustainable Design Cards: A learning Tool for Supporting Sustainable Design Strategies", Niinimäki, K. (ed.), Sustainable Fashion in a circular economy. Aalto University School of Arts, Design and Architecture, Helsinki.

Rode, J.A. et al. (2015), "From computational thinking to computational making", Proceedings of the 2015 ACM International Joint Conference on Pervasive and Ubiquitous Computing - UbiComp '15, presented at the the 2015 ACM International Joint Conference, ACM Press, Osaka, Japan, pp. 239-250. https://doi.org/ $10.1145 / 2750858.2804261$

Rowland, C. et al. (2015), Designing Connected Products: UX for the Consumer Internet of Things, O'Reilly Media.

Sanders, E. and Stappers, P. (2008), “Co-creation and the New Landscapes of Design”, CoDesign, Vol. 4, pp. 518. https://doi.org/10.1080/15710880701875068

Tedre, M. and Denning, P.J. (2016), “The long quest for computational thinking”, Proceedings of the 16th Koli Calling International Conference on Computing Education Research - Koli Calling '16, presented at the 16th Koli Calling International Conference, ACM Press, Koli, Finland, pp. 120-129. https://doi.org/ $10.1145 / 2999541.2999542$

Tissenbaum, M. et al. (2017), "Critical computational empowerment: Engaging youth as shapers of the digital future", 2017 IEEE Global Engineering Education Conference (EDUCON), presented at the 2017 IEEE Global Engineering Education Conference (EDUCON), IEEE, Athens, Greece, pp. 1705-1708. https://doi.org/10.1111/j.1756-8765.2010.01113.x

Tversky, B. (2011), "Visualizing Thought: Topics in Cognitive Science (2010)", Topics in Cognitive Science, Vol. 3 No. 3, pp. 499-535. https://doi.org/10.1111/j.1756-8765.2010.01113.x

Udoh, I.S. and Kotonya, G. (2018), "Developing IoT applications: challenges and frameworks", IET CyberPhysical Systems: Theory \& Applications, Vol. 3 No. 2, pp. 65-72. https://doi.org/10.1049/iet-cps.2017.0068

Wölfel, C. and Merritt, T. (2013), "Method Card Design Dimensions: A Survey of Card-Based Design Tools", in Kotzé, P., Marsden, G., Lindgaard, G., Wesson, J. and Winckler, M. (Eds.), Human-Computer Interaction-INTERACT 2013, Vol. 8117, Springer Berlin Heidelberg, Berlin, Heidelberg, pp. 479-486. https://doi.org/10.1007/978-3-642-40483-2_34

Yamamoto, Y., Sandström, K. and Aranda Munoz, A. (2018a). "Karakuri IoT - the concept and the result of prestudy". In Advances in Transdisciplinary Engineering. Volume 8: Advances in Manufacturing Technology XXXII. https://doi.org/10.3233/978-1-61499-902-7-311

Yamamoto, Y., Sandström, K. and Aranda Munoz, A. (2018b). "Development of methods that support exploration of simple and low-cost IoT-aided improvement solutions at manufacturing plants". In The 2018 Annual Autumn Meeting of Japan Industrial Management Association JIMA. Tokyo, Japan.

Zhao, S. et al. (2009), "Magic cards: A paper tag interface for implicit robot control", Proceedings of the 27th International Conference on Human Factors in Computing Systems - CHI 09, presented at the SIGCHI Conference, ACM Press, Boston, MA, USA, p. 173. https://doi.org/10.1145/1518701.1518730 